\title{
Superoxide Generation by Human Fetal Granulocytes
}

\author{
PETER E. NEWBURGER ${ }^{(27)}$ \\ Division of Hematology and Oncology, Children's Hospital Medical Center; Division of Pediatric Oncology, Sidney \\ Farber Cancer Institute; and Department of Pediatrics, Harvard Medical School, Boston, Massachusetts, USA
}

\begin{abstract}
Summary
Phagocytic leukocytes such as granulocytes and macrophages form an essential part of human host defense against infection by invading microorganisms. The present study demonstrates that normal fetal granulocytes undergo normal activation (i.e., the transition from the resting state to the respiratory burst) with a 75 $\pm 23 \mathrm{sec}$ lag time and generate superoxide at $6.7 \pm 2.3$ nmole $0_{2}-$ / $\mathrm{min} / 10^{6}$ cells, a rate similar to that of adult granulocytes. Fetal granulocytes also resemble adult cells in the response of the superoxide generating system to temperature change and to the chemical inhibitors N-ethyl maleimide and 2-deoxyglucose. They show the same pattern of differential effects of these perturbations on the lag time and on the rate of superoxide generation as that previously described for adult granulocytes. The process of activation, expressed as the lag time, shows no inhibition at a high temperature that diminishes by $64 \%$ the rate of superoxide production. The metabolic inhibitor 2-deoxyglucose affects only the rate and not the lag time. Both cyanide (in the presence of 2 deoxyglucose) and the sulfhydryl reagent $\mathbf{N}$-ethyl maleimide inhibit the rate equally when added before or after completion of the activation process.
\end{abstract}

\section{Speculation}

These findings provide a rationale for the observed feasibility of the prenatal diagnosis of chronic granulomatous disease and indicate that even a 16-wk fetus possesses at least this one mechanism of host defense.

Phagocytic leukocytes such as granulocytes and macrophages form an essential part of human host defense against infection by invading microorganisms. These cells respond to particulate and soluble stimuli with a "respiratory burst" of increased oxygen consumption and the production of toxic-reduced oxygen species, including superoxide $\left(\mathrm{O}_{2}^{-}\right)$, hydrogen peroxide, and hydroxyl radical (3). The primary enzymatic system involved in this process is a membrane-bound NADPH oxidase $(8,10)$. Upon stimulation of the phagocyte cell membrane, the oxidase converts from an inactive to an active form that transfers electrons from NADPH to molecular oxygen, reducing it to the free radical superoxide anion $\mathrm{O}_{2}{ }^{-}$. Failure to activate this NADPH oxidase system results in chronic granulomatous disease, a severe, often fatal, disorder characterized by recurrent bacterial and fungal infections $(13,23)$.

Previous studies in this laboratory have shown that $\mathrm{O}_{2}^{-}$production is detectable in normal fetal phagocytes and absent in those of a fetus with chronic granulomatous disease, thus permitting the prenatal diagnosis of that disorder (18). The present study examines in detail $\mathrm{O}_{2}^{-}$generation by normal fetal granulocytes. We present, with reference to adult peripheral blood granulocytes, quantitative measurements of the rate of fetal granulocyte $\mathrm{O}_{2}{ }^{-}$ generation and the kinetics of the activation process (measured by the lag time before the detection of $\mathrm{O}_{2}{ }^{-}$). We also investigate the effects on the rate and lag time of temperature, the sulfhydryl reagent $\mathrm{N}$-ethyl maleimide (NEM), and metabolic inhibitors 2deoxyglucose and cyanide. The responses are compared to those previously described in adult human (16) and guinea pig granulocytes $(5,6)$.

\section{MATERIALS AND METHODS}

Cytochrome $c$ type VI, superoxide dismutase, NEM, 2-deoxyglucose, and nitroblue tetrazolium were purchased from Sigma Chemical Co., St. Louis, MO; phorbol myristate acetate (PMA) from Consolidated Midland Chemical Co., Brewster, N.Y.; prostaglandin $F_{20}$ (tromethamine salt), from the Upjohn Co., Kalamazoo, MI; and Dextran T500 from Pharmacia Fine Chemicals, Piscataway, N.J. These and all other reagents were obtained at the highest level of purity available and used without further purification. All surfaces in contact with cells were plastic or siliconized glass, except for spectrophotometer cuvettes. Results are expressed as the mean \pm S.D. of triplicate determinations within a single experiment, unless otherwise indicated. Figures and tables therefore contain data from representative single experiments, each of which was replicated 2-10 times. S.D. reflect variation between samples or assays within each group for each individual experiment, not day-to-day variation between replicated experiments.

Cell preparation. Dr. David Kurnit generously provided peripheral blood from human fetuses at 16-19 wk gestation, as calculated from crown-rump lengths. Samples were drawn into acid-citratedextrose anticoagulant immediately following pregnancy termination induced by intra-amniotic administration of prostaglandin $F_{2 \alpha}$ (22). All pregnancy terminations were elective; no fetus was known to be at risk for any congenital disorder. Procedures and consent were approved by the Brigham and Women's Hospital Research Advisory Committee. A leukocyte fraction enriched with granulocytes was prepared as previously described (16) by sedimentation in 1\% Dextran T500 and hypotonic lysis of erythrocytes.

$\mathrm{O}_{2}^{-}$generation. Spectrophotometric measurement of $\mathrm{O}_{2}^{-}$dependent cytochrome $c$ reduction was performed in a Perkin-Elmer Model 571 double-beam spectrophotometer (Perkin-Elmer Co., Norwalk, CT) with a temperature regulator set at $37^{\circ} \mathrm{C}$, unless otherwise specified. The sample cuvette contained ferricytochrome $c(50$ nmole), granulocytes, and PMA $(1 \mu \mathrm{g})$ in $1.0 \mathrm{ml}$ of phosphate-

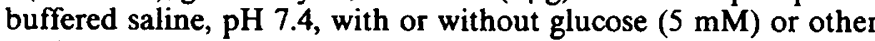
additions as indicated. The reference cuvette contained, in addition, superoxide dismutase $(20 \mu \mathrm{g})$. Cell concentrations ranged from $1 \times 10^{5}-2.5 \times 10^{6}$. The assay shows a linear response to cell number $(5,16)$ so the results could be normalized to rate of $\mathrm{O}_{2}{ }^{-}$ production per $10^{6}$ phagocytic cells. The total count of phagocytic cells was calculated by multiplying the nucleated cell count by the proportion, on differential count of cytocentrifuge smears, of polymorphonuclear leukocytes, band forms, metamyelocytes and monocytes. Typical proportions were: polymorphonuclear neutrophils $10-40 \%$, band forms $2-8 \%$, lymphocytes $40-85 \%$, monocytes $1-6 \%$, metamyelocytes $2-3 \%$, less mature myeloid cells $10-20 \%$ and erythroblasts $100-1000$ per 100 leukocytes. Nitroblue tetrazolium slide tests performed as previously described (17) confirmed the proportion of metabolically active cells. Fetal neutrophils are $95 \%$ positive in this assay (18). The rate of $\mathrm{O}_{2}^{-}$generation was calculated by dividing the linear rate of absorbance of 550 
$\mathrm{nm}\left(\Delta \mathrm{A}_{550}\right)$ by the extinction coefficient for the reduction of cytochrome $c(\Delta \in \mathrm{M}=21,000)$ (14). The lag time for activation was calculated from the intercept of the back-extrapolated linear portion of the curve with the preactivation baseline of zero absorption change $(5,16)$ (see Fig. 1). The cytochrome $c$ concentration was not rate-limiting at the cell and stimulant concentrations used.

\section{RESULTS}

The pattern of response of the fetal $\mathrm{O}_{2}^{-}$generating system was identical to that previously described in adult granulocytes (16). As illustrated in Figure 1, both adult cells $(A)$ and fetal cells $(B)$ produce no $\mathrm{O}_{2}{ }^{-}$for approximately $45 \mathrm{sec}$ after PMA stimulation. They then show a gradual rise until achievement of a linear rate. We have found the most accurate measure of this activation process to be the lag time, calculated by back-extrapolation of the linear slope (representing the rate of $\mathrm{O}_{2}{ }^{-}$production) to baseline absorbance as shown in Figure 1. Quantititave measurements of the rate and lag time (Table 1) show that fetal $\mathrm{O}_{2}^{-}$production had a rate of $\mathrm{O}_{2}^{-}$production and a similar lag time to adult values.

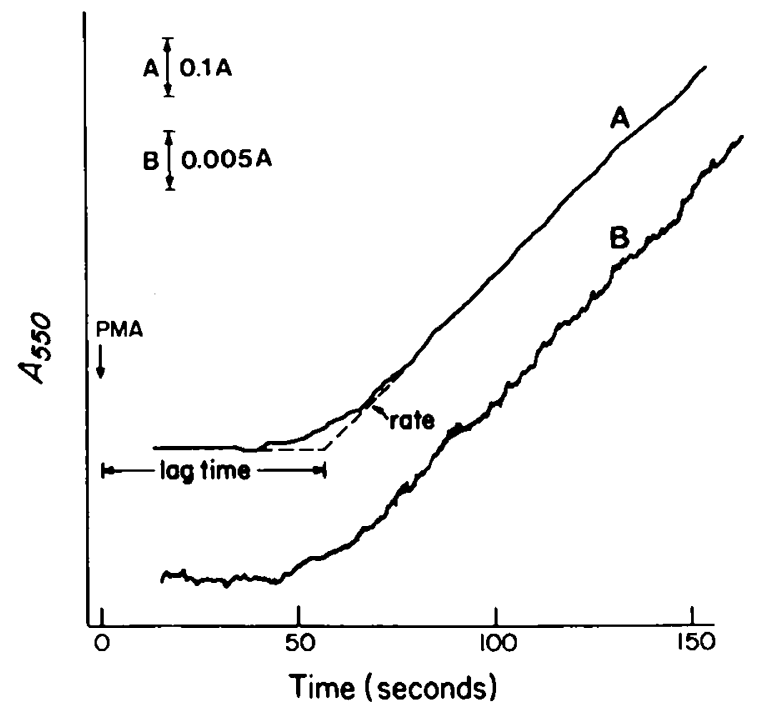

Fig. 1. Continuous recordings of $\mathrm{O}_{2}{ }^{-}$-dependent cytochrome $c$ reduction by (A) adult and (B) fetal granulocytes. PMA $(1 \mu \mathrm{g} / \mathrm{ml})$ was added at time zero and $A_{550}$ recorded as described in "Materials and Methods". The lower cell concentration of the fetal leukocytes required the expanded scale and hence lower signal-to-noise ratio. Dashed lines indicate the methods for deriving the rate of $\mathrm{O}_{2}{ }^{-}$generation (slope of the linear portion of the curve) and lag time for activation (intercept of the preactivation baseline with the back-extrapolated linear rate).

Table 1. Superoxide production by fetal and adult human granulocytes $^{\mathrm{r}}$

\begin{tabular}{lcc}
\hline & Fetal & Adult \\
\hline $\begin{array}{l}\text { Rate (nmole } \mathrm{O}_{2}{ }^{-} / \mathrm{min} / 10^{6} \text { phagocytic } \\
\text { cells) }\end{array}$ & $6.7 \pm 2.3$ & $9.3 \pm 2.5$ \\
$\begin{array}{l}\text { Lag time (sec) } \\
\text { Rate after addition of N-ethyl maleimide }\end{array}$ & $75 \pm 23$ & $65 \pm 16$ \\
$\quad$ Before activation & $<0.05$ & $<0.005$ \\
$\quad$ After activation & $<0.05$ & $<0.005$ \\
\hline
\end{tabular}

'Superoxide production was continuously monitored after the addition of phorbol myristate acetate to the assay mixture described in "Materials and Methods." Results for rate and lag time are expressed as the mean \pm S.D. for 12 fetal and 10 adult samples. Superoxide production was undetectable when monitored in the presence of N-ethyl maleimide $(0.2$ $\mathrm{mM}$ ) added to phorbol myristate acetate ("before activation") or upon the achievement of a linear rate of superoxide production 120-180 sec later ("after activation"). Comparison of fetal and adult rates and lag times by two-tailed $t$ test yields $P$ values of 0.02 and 0.25 , respectively.

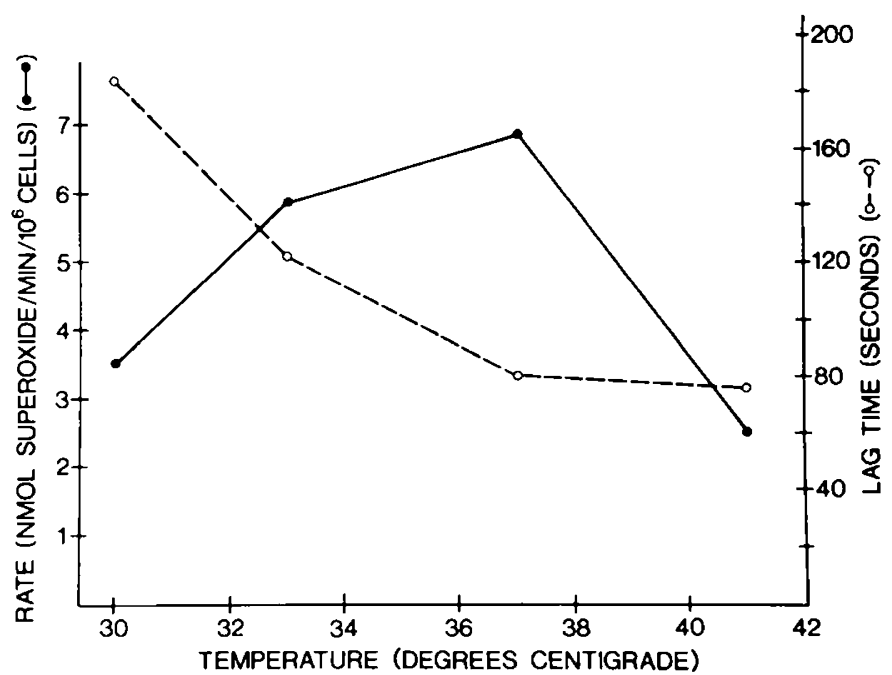

Fig. 2. The effect of temperature on the rate $(\Theta)$ and lag time $(O)$ of PMA-stimulated $\mathrm{O}_{2}{ }^{-}$production by human fetal granulocytes. Each point represents the mean of triplicate determinations with less than $10 \%$ variability.

The effect of temperature on the rate and lag time for $\mathrm{O}_{2}{ }^{-}$ production by fetal phagocytes is illustrated in Figure 2 . The rate of $\mathrm{O}_{2}^{-}$production was maximal at $37^{\circ} \mathrm{C}$, with less $\mathrm{O}_{2}^{-}$produced at both lower and higher temperatures; however, the lag time progressively shortened (indicating more rapid activation) as the temperature rose, even to the $41^{\circ} \mathrm{C}$ level that slowed the rate.

The sulfhydryl reagent NEM at $0.2 \mathrm{mM}$ concentration completely blocked $\mathrm{O}_{2}{ }^{-}$production by fetal phagocytes. As shown in Table 1, this inhibition occurred both when NEM was present at the time of stimulation and when it was added after completion of activation (i.e., upon achievement of a linear rate of $\mathrm{O}_{2}{ }^{-}$generation).

Incubation with 2-deoxyglucose, an inhibitor of glycolysis, caused a dose-dependent inhibition of $\mathrm{O}_{2}{ }^{-}$production. As shown in the lower panel of Figure 3, both fetal (solid circles, solid line) and adult (open circles, solid line) granulocytes diminished their rates of $\mathrm{O}_{2}^{-}$production after incubation with 2-deoxyglucose and these rates diminished still further in the presence of $0.5 \mathrm{mM}$ sodium cyanide (solid and open squares, dashed lines). The added inhibition was identical whether the cyanide was added before or after activation. In contrast, the lag times for activation (upper panel of Figure 3) underwent no significant change over the range of 2-deoxyglucose concentrations utilized $(P>0.1$ by $t$ test for all possible pairs).

Incubation of adult granulocytes with prostaglandin $F_{2 a} 50 \mu \mathrm{g} /$ $\mathrm{ml}$, a maximal fetal level (11), for up to $30 \mathrm{~min}$ had no significant effect on the rate or lag time for $\mathrm{O}_{2}^{-}$production.

\section{DISCUSSION}

Infection presents a major threat to the survival of neonates, so many studies have investigated the properties of newborn host defense mechanisms. Neonatal granulocytes show diminished in vitro chemotactic responses (15), bactericidal activity (24), chemiluminescence (21), and oxidizing radical production (2) but normal $\mathrm{O}_{2}^{-}$generation (2). The defects are most pronounced in infected or otherwise stressed newborns (20). Our previous study of fetal leukocytes (18) showed that normal 16-20 wk fetal granulocytes are capable of $\mathrm{O}_{2}^{-}$generation, nitroblue tetrazolium reduction, and that the defect of activation that causes chronic granulomatous disease affects the fetal as well as adult respiratory burst mechanism.

The present study demonstrates that normal fetal granulocytes undergo normal activation (i.e., the transition from the resting state to the respiratory burst) and generate $\mathrm{O}_{2}^{-}$at a rate similar to 


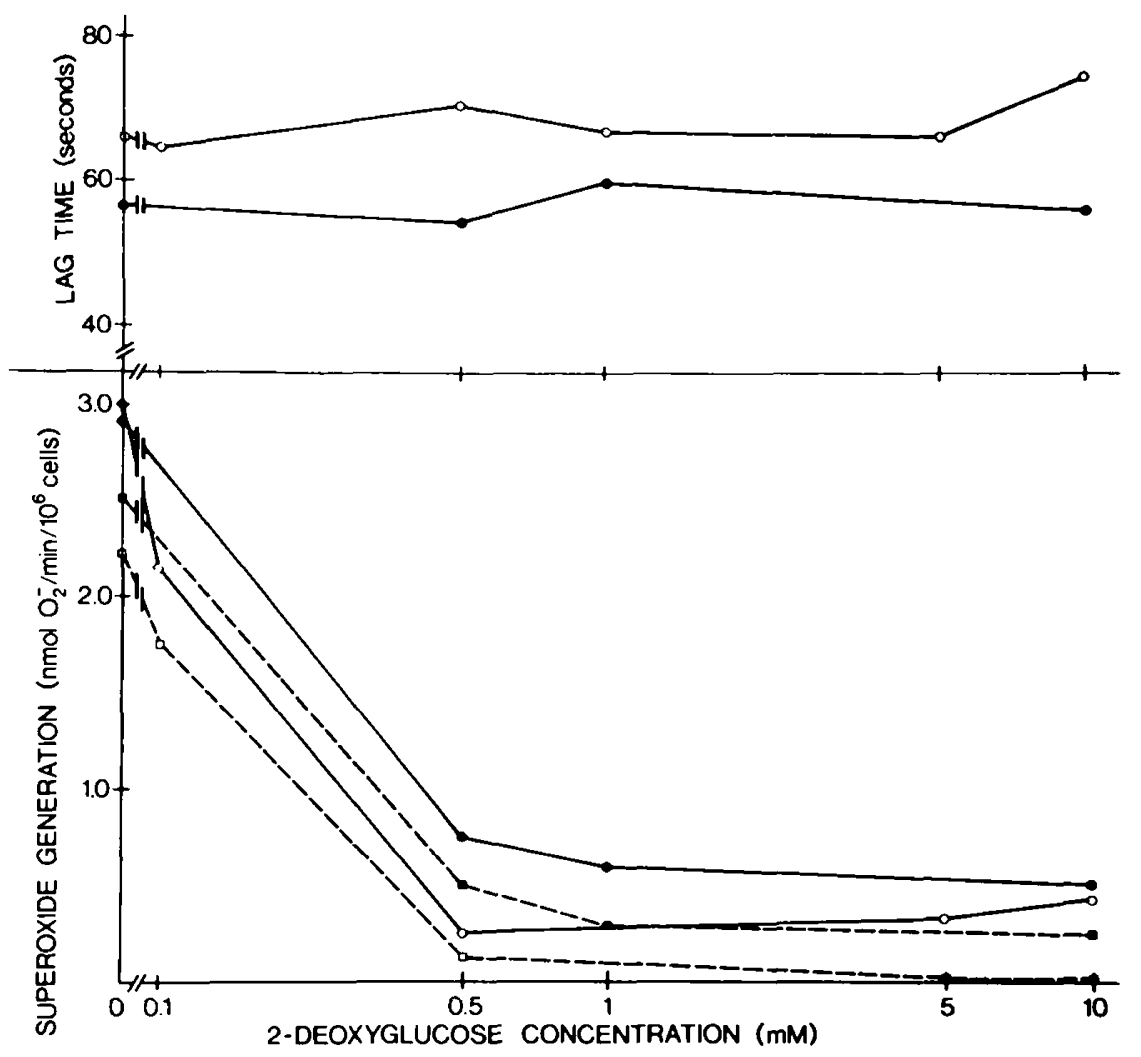

Fig. 3. The effect of 2-deoxyglucose on the lag time and rate of PMA-stimulated $\mathrm{O}_{2}^{-}$production by adult and fetal granulocytes. Upper panel lag times for adult $(O)$ and fetal $(\Theta)$ granulocytes. Lower panel, rates for adult granulocytes in the absence $(O-O)$ and presence $(\square----\square)$ of $0.5 \mathrm{mM}$ $\mathrm{NaCN}$ and for fetal granulocytes in the absence $(-)$ and presence (-.- of $\mathrm{NaCN}$. In this experiment NaCN was added prior to PMA activation; identical results were obtained with $\mathrm{NaCN}$ added $120 \mathrm{sec}$ after PMA. Each point represents the mean of triplicate determinations within $10 \%$ of each other.

that of adult granulocytes. Both the kinetic characteristics and the duration of the activation process, expressed as the lag time, are virtually identical for fetal and adult granulocytes. The rate of $\mathrm{O}_{2}{ }^{-}$ generation by fetal granulocytes is slightly, but significantly, less than that of adult granulocytes. This difference probably derives from the inclusion in the fetal "granulocyte" count of metamyelocytes and monocytes that produce less $\mathrm{O}_{2}^{-}$than fully mature granulocytes (25; P. E. Newburger, and H. J. Cohen, unpublished data). In addition, fetal bone marrow, which leaks many immature cells into the peripheral blood, may release granulocytes that would constitute the storage pool of an adult marrow. Such cells have been shown to be inferior to peripheral blood granulocytes in nitroblue tetrazolium reduction (25) and ingestion capacity (1). The release of this storage pool in stressed neonates might also explain the well-known defects in granulocyte function $(2,15,20$, $21,24)$ and diminished bone marrow reserved (4) of infected newborns.

Fetal granulocytes also resemble adult cells in the response of the $\mathrm{O}_{2}{ }^{-}$generating system to temperature change and to the chemical inhibitors NEM and 2-deoxyglucose. They show the same pattern of differential effects of these perturbations on the lag time and on the rate of $\mathrm{O}_{2}^{-}$generation as that previously described for adult granulocytes (16). The process of activation, expressed as the lag time, shows no inhibition at a high temperature that profoundly diminishes the rate of $\mathrm{O}_{2}^{-}$production. The metabolic inhibitor 2-deoxyglucose affects only the rate and not the lag time. Both cyanide (in the presence of 2-deoxyglucose) and the sulfhydryl reagent NEM inhibit the rate equally when added before or after completion of the activation process, a finding noted in adult human (16) but not in guinea pig (6) granulocytes. Thus in fetal, as in adult human granulocytes, activation (measured as the lag time) and activity (measured as the rate) of the $\mathrm{O}_{2}{ }^{-}$generating system are separable processes. These studies utilized PMA, a soluble stimulator, to initiate the respiratory burst.
Although not as truly a "physiologic" stimulus as a microorganism, PMA induces a metabolic response qualitatively and quantitatively similar to that induced by opsonized particles such as zymosan $(7,9)$. Its triggering mechanism, however, may bypass that of opsonized particles (12). Therefore, our results with PMAstimulated fetal granulocytes indicate that these cells possess the NADPH oxidase system that generates $\mathrm{O}_{2}^{-}$, but do not necessarily have the triggering mechanism necessary for its physiologic function in vivo.

Overall, fetal and adult $\mathrm{O}_{2}^{-}$generation appear identical in both activation and activity. Such identity differs from the important switches that take place in erythrocyte hemoglobin, enzymes, and antigens (19). These findings provide a rationale for the observed feasibility of the prenatal diagnosis of chronic granulomatous disease and indicate that even a 16-ivk fetus probably possesses at least this one mechanism of host defense.

\section{REFERENCES AND NOTES}

1. Altman, A. J. and Stossel, T. P.: Functional immaturity of bone marrow bands and polymorphonuclear leukocytes. Br. J. Haematol., 24: 241 (1974).

2. Ambruso, D. R., Altenburger, K. M., and Johnston, R. B., Jr.: Defective oxidative metabolism in newborn neutrophils: discrepancy between superoxide anion and hydroxyl radical generation. Pediatrics, 64: 722 (1979).

3. Babior, B. M.: Oxygen-dependent killing by phagocytes. N. Engl. J. Med., 298: 659, 721 (1978)

4. Christensen, R. D. and Rothstein, G.: Exhaustion of mature marrow neutrophils in neonates with sepsis. J. Pediatr., 96: 316 (1980).

5. Cohen, H. J. and Chovaniec, M. E.: Superoxide generation by digitonin-stimulated guinea pig granulocytes. A basis for a continuous assay for monitoring superoxide production and for the study of the activation of the generating systems. J. Clin. Invest., 61: 1081 (1978).

6. Cohen, H. J. and Chovaniec, M. E.: Superoxide production by digitonin-stimulated guinea pig granulocytes. The effects of $\mathrm{N}$-ethyl maleimide, divalent cations, and glycolytic and mitochondrial inhibitors on the activation of the superoxide generating system. J. Clin. Invest., 61: 1088 (1978).

7. Cohen, H. J., Newburger, P. E., Chovaniec, M. E., Whitin, J. C. and Simons, E S.: Opsonized zymosan-stimulated granulocytes-activation and activity of the 
superoxide generation system and membrane potential changes. Blood, 58: 975 (1981).

8. DeChatelet, L. R., McPhail, L. C., Mullikin D., and McCall, C. E.: An isotopic assay for NADPH oxidase activity and some characteristics of the enzyme from human polymorphonuclear leukocytes. J. Clin. Invest., S5: 714 (1975).

9. DeChatelet, L. R., Shirley, P. S., and Johnston, R. B. Jr.: Effect of phorbol myristate acetate on the oxidative metabolism of human polymorphonuclear leukocytes. Blood, 47: 545 (1976).

10. Dewald, B., Baggiolini, M., Curnutte, J. T., and Babior, B. M.: Subcellular localization of the superoxide-forming enzyme in human neutrophils. J. Clin. Invest., 63: 21 (1979).

11. Green, K., Granstrom, E., Bygdeman, M., and Wiqvist, N.: Kinetic and metabolic studies of 15-methyl-prostaglandin $\mathrm{F}_{2 a}$ administered intraamniotically for induction of abortion. Prostaglandins, 11: 699 (1976).

12. Harvath, L. and Andersen, B. R.: Defective initiation of oxidative metabolism in polymorphonuclear leukocytes. N. Engl. J. Med., 300: 1130 (1979).

13. Johnston, R. B., Jr. and Baehner, R. L.: Chronic granulomatous disease: correlation between pathogenesis and clinical findings. Pediatrics, 48: 730 (1971).

14. Massey, V.: The microestimation of succinate and the extinction coefficient of cytochrome C. Biochim. Biophy. Acta, 34: 255 (1959).

15. Miller, M. E.: Chemotactic function in the human neonate: humoral and cellular aspects. Pediatr. Res., 5: 487 (1971).

16. Newburger, P. E., Chovaniec, M. E., and Cohen, H. J.: Activity and activation of the granulocyte superoxide-generating system. Blood, 55: 85 (1980).

17. Newburger, P. E., Chovaniec, M. E., Greenberger, J. S., and Cohen, H. J.: Functional changes in human leukemia cell line HL-60: a model for myeloid differentiation. J. Cell Biol., 82: 315 (1979).

18. Newburger, P. E., Cohen, H. J., Rothchild, S. B., Hobbins, J. C., Malawista, S. E., and Mahoney, M. J.: Prenatal diagnosis of chronic granulomatous disease. N. Engl. J. Med., 300: 178 (1979).

Copyright $(1) 1982$ International Pediatric Research Foundation, Inc. 0031-3998/82/1605-0373\$02.00/0
19. Oski, F. A.: The unique fetal red cell and its function. Pediatrics, 51: 494 (1973)

20. Shigeoka, A. O., Santos, J. I., and Hill, H. R.: Functional analysis of neutrophil granulocytes from healthy, infected and stressed neonates. J. Pediatr., 95: 454 (1979)

21. Strauss, R. G., Rosenberger, T. G., and Wallace, P. D.: Neutrophil chemiluminescence during the first month of life. Acta Haematol., 63: 326 (1980).

22. Stubblefield, P. G., Naftolin, F., Frigoletto, F., and Ryan V. J.: Laminaria augmentation of intra-amniotic $\mathrm{PGF}_{2 \alpha}$ for midtrimester pregnancy termination. Prostaglandins, 10: 413 (1975).

23. Whitin, J. C., Chapman, C. E., Simons, E. R., Chovaniec, M. E., and Cohen H. J.: Correlation between membrane potential changes and superoxide production in human granulocytes stimulated by phorbol myristate acetate. Evidence for defective activation in chronic granulomatous disease. J. Biol. Chem., 255: 1874 (1980).

24. Wright, W. C., Jr., Ank, B. J., Herbert, J., and Steihm, E. R.: Decreased bactericidal activity of leukocytes of stressed newborn infants. Pediatrics, 56: 579 (1975).

25. Zakhireh, B. and Root, R. K.: Development of oxidase activity by human bone marrow granulocytes. Blood, 54: 429 (1979).

26. We thank Dr. Harvey J. Cohen and Dr. David G. Nathan for continued support and encouragement, Ms. Susan Hansen for technical assistance, and Ms. Barbara Splane and Ms. Catherine Lewis for manuscript preparation.

27. Requests for reprints should be addressed to: Dr. Peter E. Newburger, Department of Pediatrics, University of Massachusetts Medical Center, 55 Lake Avenue North, Worcester, MA 01605

28. This research was supported by PHS grants 26033 and 26506 awarded by the National Cancer Institute, DHHS, and by a Basil O'Connor Starter Research Grant from the March of Dimes-Birth Defects Foundation.

29. Received for publication July 2, 1981.

30. Accepted for publication October 22, 1981. 